Sharif University of Technology
Scientia Iranica
SCIENTIA
IRAN I CA
http://scientiairanica.sharif.edu

Research Note

\title{
The effect of fixed-tip piles on stabilization of earth slopes
}

\author{
M. Hajiazizi ${ }^{a, *}$, M. Nasiri ${ }^{\mathrm{a}}$, and A.R. Mazaheri ${ }^{\mathrm{b}}$ \\ a. Department of Civil Engineering, Razi University, Taq-e Bostan, Kermanshah, Iran. \\ b. Department of Civil Engineering, Ayatollah Boroujerdi University, Boroujerd, Iran. \\ Received 12 October 2016; received in revised form 5 January 2017; accepted 3 July 2017
}

\author{
KEYWORDS \\ Earth slope; \\ Fixed-tip pile; \\ Pile length reduction; \\ Stabilization; \\ Experimental \\ modeling.
}

\begin{abstract}
A recent widely researched solution is slope stabilization using a row of piles. In this study, the effects of fixed-tip pile and the subsequent pile length reduction, which finally bring about a reduction in stabilization costs, were considered. This paper presents novel analyses that were carried out in static condition. The analyses were performed using the Limit Equilibrium (LE) method and Shear Strength Reduction (SSR) method, which approved one another. Fixing pile tip was an efficient and applicable method for stabilizing earth slopes and reducing pile length. Results of these analyses were acceptable and properly consistent with the results obtained by other researchers. The process of fixing the end of the pile was also carried out experimentally and a new method was proposed for this purpose that, besides being simple, was cost-effective and practical. The result of this investigation showed the effectiveness of the proposed method, in which fixing the pile tip could enhance Factor of Safety (FoS) up to $55 \%$.
\end{abstract}

(C) 2018 Sharif University of Technology. All rights reserved.

\section{Introduction}

Installing piles for stabilizing endangered earth slopes is an effective way for preventing the imbalance of force and instability. Slope stability analysis [1-4] and reinforcing the slopes using piles [5-7] are among the major issues to be addressed in geotechnical engineering.

Stabilization of sliding and imbalanced earth slopes is more complicated and costly. Stabilizing effect by using pile is provided by the passive resistance of the pile below the slip surface and load transfer from the sliding mass to the underlying stationary soil or

*. Corresponding author. Tel./Fax: 08334283264

E-mail addresses: mhazizi@razi.ac.ir (M. Hajiazizi);

nasiri.ma@razi.ac.ir (M. Nasiri); a.mazaheri@abru.ac.ir (A.R. Mazaheri)

doi: $10.24200 /$ sci.2017.4211 rock formation through the piles due to soil arching mechanism [8-13].

Kourkoulis et al. [14] divided pile-based stabilization methods for earth slopes into the following two categories:

1. Displacement-or pressure-based methods [15-20];

2. Numerical methods $[17,21-23]$.

Moreover, slope stability and optimizing pile location by installing a row of piles [16,19,24-28] have been studied by many researchers. It is shown that internal friction angle is the most influential parameter in the slope stability analysis of finite slopes [29]. Kourkoulis et al. [14] developed a hybrid methodology for the design of slope-stabilizing piles. This method combined the rigor of $3 D$ finite element simulation with the simplicity of widely accepted analytical techniques. The piles were embedded in the stable soil by the length of $5 D$ ( $D=$ pile diameter $)$, because the zone 
of influence of each pile had been demonstrated not to exceed $5 D$ and the length of the pile was restricted to $10 D$. Fixing pile end helped to have a pile length shorter than the length proposed by Kourkoulis [14] and diminished stabilization costs.

Ito and Matsui [16] developed a plastic extrusiondeformation model for rigid piles of infinite length (not closely spaced) to estimate the shear resistance offered by a row of piles embedded in a slope. Their approach presumed that the soil was soft and deformed plastically around piles. Despite its rigor, the method neglected pile flexibility, pile limited length, and soil arching phenomena that might all have a substantial effect [14]. Hassiotis et al. [17] presented the friction circle method by defining new expressions for the stability number to incorporate the pile resistance in slope stability analysis using a closed form solution of the beam equation. The ultimate force intensity (soilpile pressure) was calculated based on the equations proposed by Ito and Matsui [16] assuming a rigid pile. The Finite Difference Method (FDM) was used to analyze the pile section below the critical surface as a beam on elastic foundations. However, the safety factor of the slope after inserting the piles was obtained based on the new critical failure surface, which was not necessarily the one before pile installation [30]. Poulos [19] introduced a method of analysis in which a simplified form of boundary element method [31] was employed to study the response of a row of passive piles incorporated in limit equilibrium solutions of slope stability; in these solutions, the pile was modeled as a simple elastic beam and the soil as an elastic continuum [32]. The method evaluated the maximum shear force that each pile could provide based on an assumed input free field soil movement and computed the associated lateral response of the pile. The prescribed soil movements were employed by considering the compatibility of the horizontal movement of the pile and soil at each element. While pile and soil strength and stiffness properties were taken into account to obtain soil-pile pressure in this method, group effects, namely, piles spacing, were not considered in the analysis of soil-pile interaction. Poulos [19] proposed a 12-meter pile; such length of reinforcing element would significantly increase the stabilization costs. Won et al. [33] presented a numerical comparison of predictions by limit equilibrium analysis and $3 D$ numerical analysis for a slope-pile system. The length of pile was considered to be up to the end of embankment without any limitation. Installation of such a pile not only added to the implementation costs, but also made it difficult to choose the appropriate pile length. Ausilio et al. [34] proposed a pile length two times the height of the pile above the slip surface. This proposed length not only was conservative, but also added to stabilization costs.

Fixing the pile end using cement grout is pre- sented in this work for the first time. The effects of cement grout and cement treatment on soil strength have been investigated by many researchers $[35,36]$.

It is worth mentioning that under reamed piles are better than conventional piles; however, discontinuity of the piles and the surrounding soil is one of their disadvantages. This defect has been fixed in the proposed method (fixed pile tip) and a significant continuity is created between the pile and its surrounding soil. As a result, deformations are less under equal loading.

This paper studies the effect of fixed pile tip on factor of safety and pile length reduction by using the LE method and the SSR method in static analysis.

\section{Shear Strength Reduction (SSR) method}

The safety factor of a slip surface is defined as the reduction factor by which the original soil shear strength parameters should be reduced to make the slope reach the critical failure state [37].

The reduced shear strength parameters, $C_{f}^{\prime}$ and $\phi_{f}^{\prime}$, are given as follows:

$$
\begin{aligned}
C_{f}^{\prime} & =\frac{C^{\prime}}{\mathrm{FoS}}, \\
\phi_{f}^{\prime} & =\arctan \left(\frac{\tan \phi^{\prime}}{\mathrm{FoS}}\right),
\end{aligned}
$$

where $C^{\prime}$ and $\phi^{\prime}$ are the cohesion and internal friction angle of the soil, respectively; $C_{f}^{\prime}$ and $\phi_{f}^{\prime}$ are the mobilized cohesion and internal friction angle of the slope required to attain the state of critical stability, respectively.

There is another definition of the FoS for SSR method by which the load or gravity is increased by a certain factor to bring the slope to the critical failure state [37].

This definition of FoS is exactly the same as that used in limit equilibrium methods and has been adopted in many other studies [8,11,14,38-40]. Herein, FoS can also be understood as the factor by which the soil shear strength parameters are reduced to give rise to incipient failure. According to the kinematic theory of limit analysis, the factor of safety determined by equating the rate of external work to the rate of internal energy dissipation for any kinematically admissible velocity field is not less than the true solution to slope stability analysis. Thus, the safety factor can be calculated by minimizing FoS with all kinematically admissible failure mechanisms. When a row of piles is inserted in a slope, the additional resistance that each pile can provide depends on the soil strength. It is suggested that the retaining force be calculated with the reduced values of $C^{\prime}$ and $\phi^{\prime}$ to get conservative results in the design of piled slopes. 


\section{Pile length optimization}

Pile length has a considerable effect on slope stabilization costs. Hence, it is tried to reduce pile length to the extent that it does not significantly affect the growth of factor of safety. In order to determine the optimal pile length, it is necessary to calculate the factor of safety associated with each of the proposed length values. First, the pile tip is fixed based on different length values and then, the variations of factor of safety and the pile length are obtained. Finally, a comparison is made between results obtained from fixed and free pile ends.

\section{Effect of fixed pile end on factor of safety and pile displacement}

A useful solution to reduce pile length and displacement, diminish stabilization costs, and increase factor of safety (especially that of soft soils) is to fix pile ends. This new solution is introduced in this paper. It can drastically reduce pile length and displacement, and increase factor of safety. Although implementation of this solution is associated with specific problems, it yields very good results that justify its implementation. Piles with different lengths are fixed. Then, the shortest pile length is chosen and implementation costs are reduced as a result.

\section{Determining the most effective and economical location for pile installation}

Although increase in factor of safety is known as an objective of pile-based slope stabilization, it is not its only objective, because costs reduction is another definite objective of any project. Therefore, the best location for pile installation is a place that not only gives the required factor of safety, but also provides for determination of the shortest pile length. Choosing such a location reduces costs as well. The location chosen by the described process is known as the most effective location for pile installation. In order to find the optimal location, the three-dimensional diagram of pile length, pile location, and factor of safety is prepared. The diagram can be used for determining the minimum pile length with the desirable factor of safety.

\section{Fixing the pile tip}

\subsection{Literature review of fixing the pile}

Fixing the pile tip using cement grout has been presented in this work for the first time. The effects of cement grout and cement treatment on soil strength were investigated by many researchers $[35,36]$. Fixing the pile head (not pile tip) was investigated by some researchers $[41,42]$.

\subsection{Procedure of fixing the pile tip}

The box used for the tests is shown in Figure 1. In order to construct a fixed pile tip in slopes, a new method is presented here, which is described below. To this end, prefabricated pile, a case with larger diameter than pile element and cement slurry, is needed. At first, the pile is placed at the optimal location in slope and the case is inserted around it (Figure 2); then, the embankment construction around case is performed in

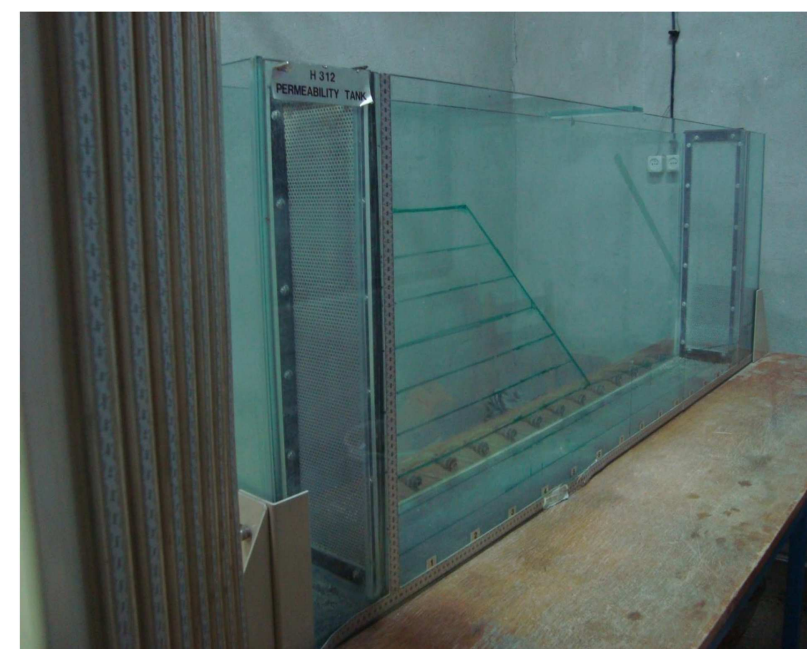

Figure 1. Experimental box and piezometers panel.
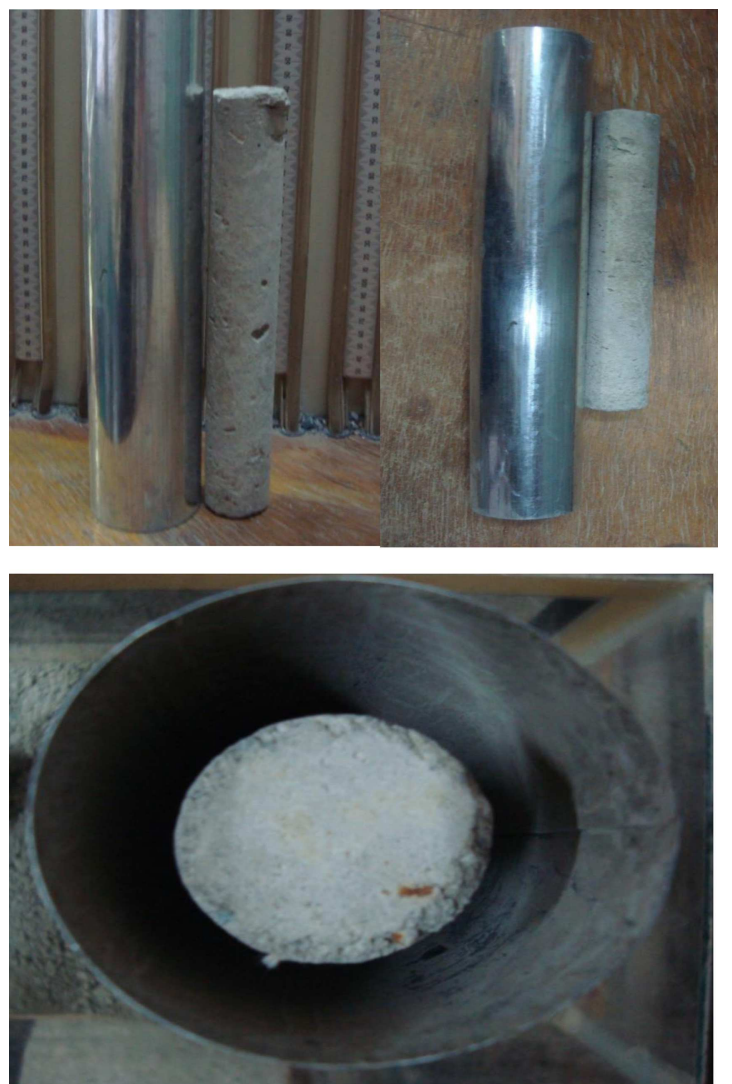

Figure 2. Prototype of a pile, a case, and placement of the case around the pile. 
multiple steps (the total height of fixed end region must be divided into several smaller heights to simplify the process). At the end of each phase, the cement slurry is injected into the surrounding soil through the case. It is worth mentioning that the fixing of the pile tip can be implemented in one step. If a larger lateral surface of the pile tip needs to be fixed, it is recommended to implement fixing operation in several steps and lift the case in each step. For example, in order to fix the end of pile with $50 \mathrm{~cm}$ diameter up to 3 times its diameter (fixed end depth is $150 \mathrm{~cm}$ ), the steps of construction are divided into 3 phases. At first, the pile and the case are inserted in the optimal location and the primary $50 \mathrm{~cm}$ of soil layer around the case is filled; then, the cement grout is poured into the case. Afterwards, the case is pulled out approximately up to surface layer. By doing this, the cement grout in the case is radially spread and it penetrates in the pile's surrounding soil. Then, the second $50 \mathrm{~cm}$ layer is embanked and after completion of filling, the cement slurry is poured into case. Then, the case is removed up to near surface in order to inject cement slurry in the surrounding soil. After the second phase, same as before, the last $50 \mathrm{~cm}$ of soil layer is embanked and cement grout is poured in the case. Same as pervious, the case is pulled out and cement slurry is spread into subsoil. By reaching the intended height to create the fixed pile tip, the case is completely removed and embankment is performed in ordinary condition. Figure 3 shows the process of constructing a fixed pile tip in practice.

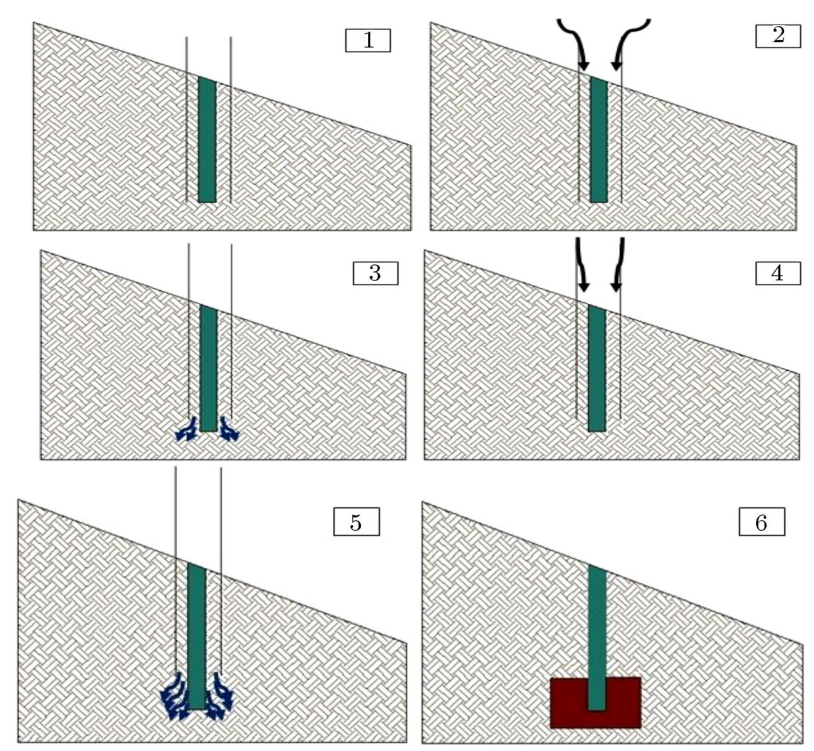

Figure 3. Fixed pile tip construction process: (1) inserting the case around the pile; (2) pouring cement slurry into the case; (3) pulling out the case in order to inject the cement grout in subsoil; (4) next phase of pouring cement slurry in the case; (5) next phase of pulling out the case; and (6) final removal of case and fixed-end pile creation after cement grout treatment (brown zone is the integrated area where the pile tip is fixed).
This originality in providing fixed-tip condition for pile leads to the formation of a rigid and integrated zone around pile end after cement slurry treatment (Figure 4), which causes dramatic increase in resistance against loads in this region.

In order to reach certainty about fixed-end pile performance, two experimental tests were carried out in sandy slopes; the first one was a slope reinforced with free-end pile and the second one was reinforced slope in presence of fixed-end pile constructed by this approach.

In the first model, a prefabricated pile with the diameter of $3.6 \mathrm{~cm}$ was placed in the middle of slope and embankment was constructed. Then, after precipitation, loading process began; the critical failure stress was obtained at $10.66 \mathrm{kPa}$.

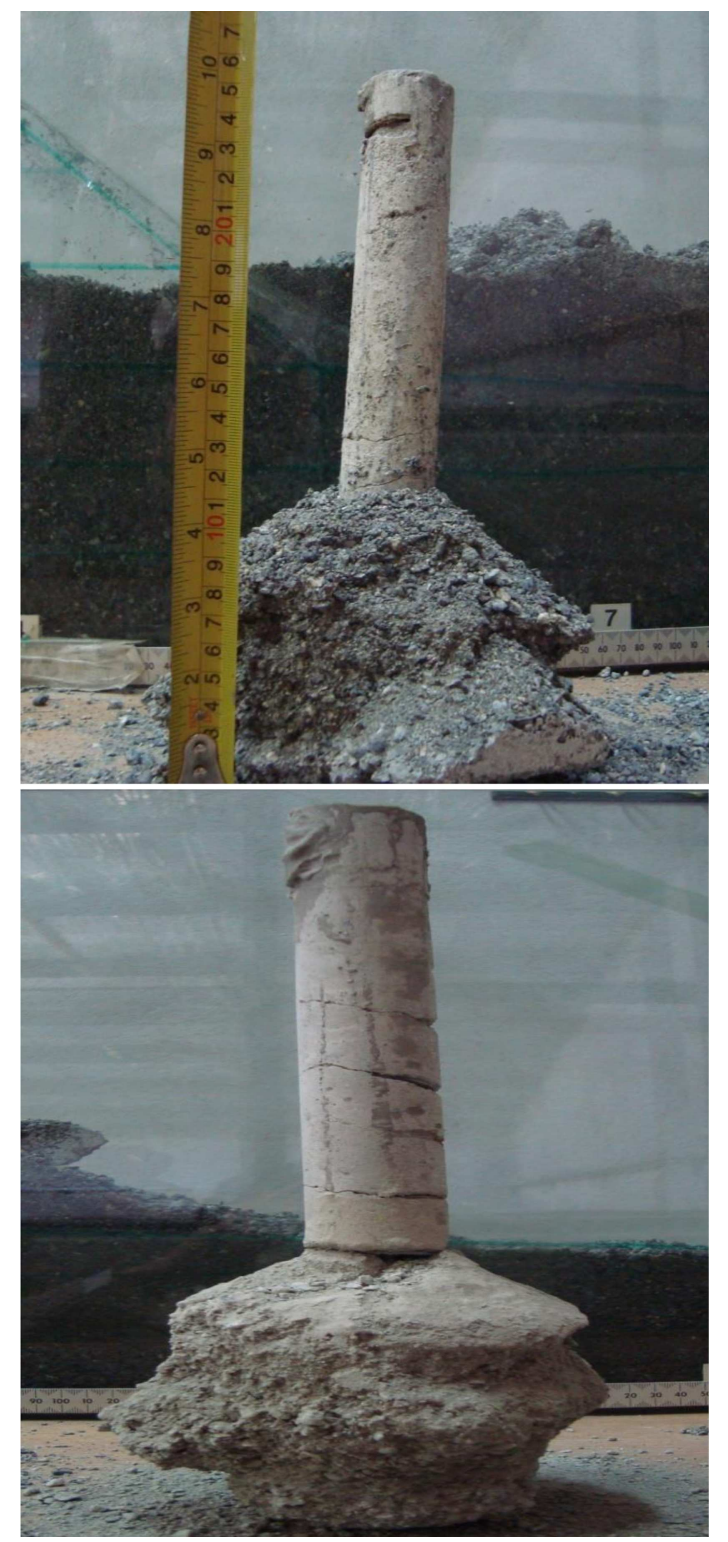

Figure 4. Fixed pile tip construction after the cement slurry treatment proposed in this paper. 
In the second model, slope geometry, and soil and pile properties were the same as those in the first model and a case with the diameter of $5.5 \mathrm{~cm}$ was used for provision of fixed-end condition. The purpose was to create a fixed pile tip with the height of three times the pile diameter $(10.8 \mathrm{~cm})$. In order to do that, embankment layers were applied in three phases (each step with embankment height of $3.6 \mathrm{~cm}$ ). The first layer was embanked and cement slurry was poured into case. Then, the second step of embankment construction was performed. After the end of the second phase, the case was pulled out about $3 \mathrm{~cm}$ in order to inject the cement slurry through surrounding soil. Then, the next step of cement grout purring was carried out. These cycles were repeated until reaching the final height of fixity $(10.8 \mathrm{~cm})$ in the end of pile. Then, the case was completely removed and, same as in the construction of the free tip pile, the remaining parts of slope were constructed. After precipitation, loading process was began; in this condition, the critical failure stress was obtained at $19.85 \mathrm{kPa}$ (Figure 5 ).

The results indicate that by using the simple and effective method proposed in this paper, the pile end can be fixed and, due to that, bearing capacity and stability of slope significantly increase. Comparing these two experimental tests confirmed the effectiveness of fixed-tip pile. Moreover, construction procedures of this reinforcing model were simple to execute.

Variations of loading with displacement of pile head for free-end and fixed-end piles are shown in
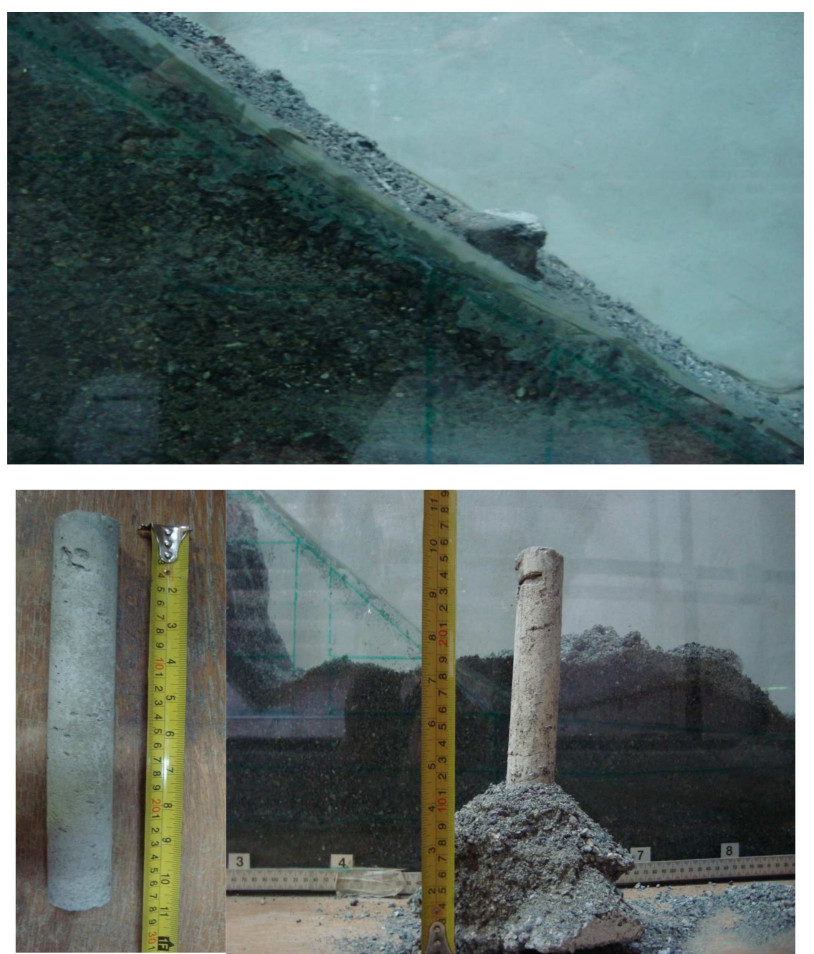

Figure 5. Fixed pile tip in an earth slope (critical stress $=19.85 \mathrm{kPa})$.

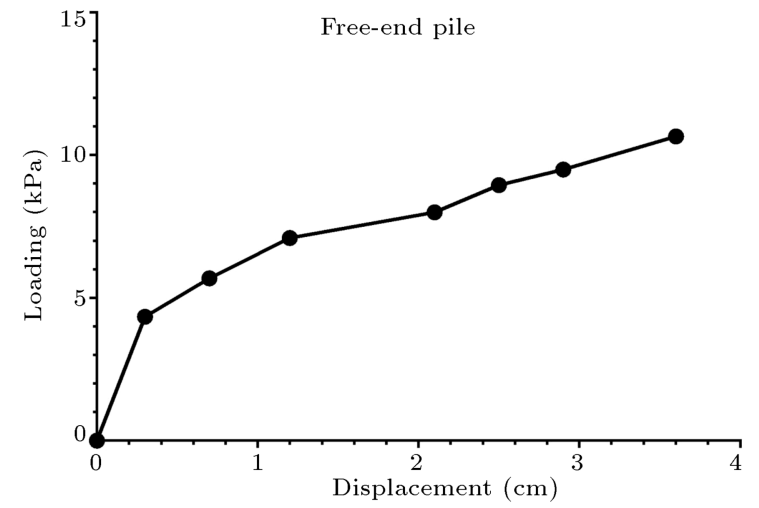

Figure 6. Variations of loading with displacement of pile head for free-end pile.

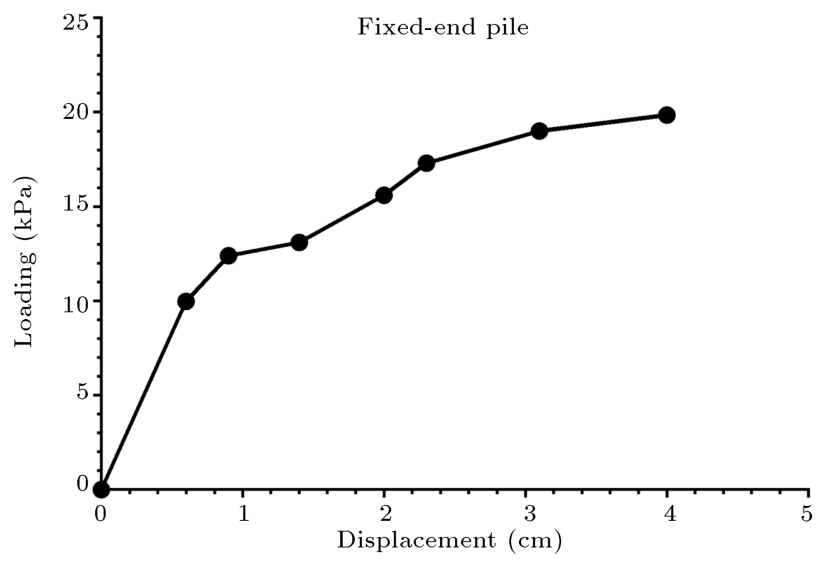

Figure 7. Variations of loading with displacement of pile head for fixed-end pile.

Figures 6 and 7, respectively. Also, variations of loading with time for fixed-end pile are shown in Figure 8.

\section{Numerical examples}

\subsection{Example 1}

The inclined surface studied in this example is depicted in Figure 9. The embankment height is equal to $13.7 \mathrm{~m}$ and its slope is 30 degrees. The unit weight is $19.63 \mathrm{kN} / \mathrm{m}^{3}$, angle of friction is 10 degrees, cohesion is equal to $23.94 \mathrm{kN} / \mathrm{m}^{2}$, modulus of elasticity is $12000 \mathrm{kN} / \mathrm{m}^{2}$, and Poisson's ratio is 0.3 .

\subsubsection{Analysis of the effect of fixed-tip pile}

The fixed pile ends method, which is introduced as a new method in this paper, can considerably change the value of the factor of safety. In two- or multi-layer slopes, whose lowest layer has a proper density, the adequate reliability can be obtained by embedding the pile end in the dense layer. However, in the case of homogenous slopes, other methods proposed by some other researchers can be used for reliability purposes. Lee et al. [42] suggested that, in order to achieve the 


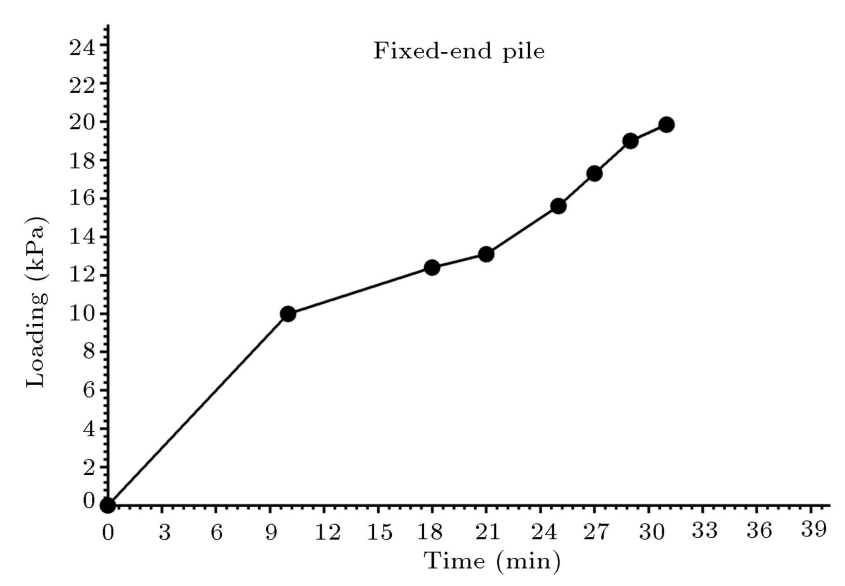

Figure 8. Variations of loading with time for fixed-end pile.

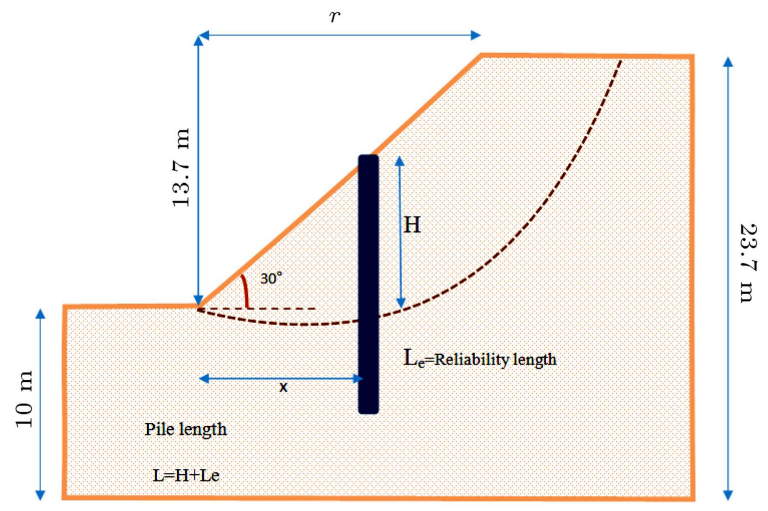

Figure 9. Slope geometry in Example 1 and pile reliability length $\left(L_{e}\right)$ under critical slip surface.

reliability length $\left(L_{e}\right)$, the pile should be embedded in the layer below the critical slip surface to a depth equal to $H$ (distance between the critical failure surface and the ground surface).

Kourkoulis et al. [14] believed that the pile reliability length $\left(L_{e}\right)$ could be $5 D$ at most. Reese and Van [30] also indicated that the effective zone on each pile beneath the critical slip surface did not exceed $5 D$.

In Figure 10, the critical slip surface for LE and SSR methods is shown. Figure 11 shows the comparison of the results of the SSR method used for free-end and fixed-end piles with a length of $L=1.5 \mathrm{H}$. As seen in this figure, fixing pile end has a significant effect on the growth of the factor of safety. A fixed pile end can increase the value of the factor of safety up to $55 \%$.

Figure 12 shows the comparison between the results obtained by the SSR method for a row of piles with a length of $1.5 \mathrm{H}$ and the results obtained for a row of free-end piles with a length of $2 H$ in [25]. As seen in this figure, in spite of the short length of the pile, fixing the pile end has led to a considerable increase in the value of factor of safety. Hence, by diminishing the pile length and adding to the factor

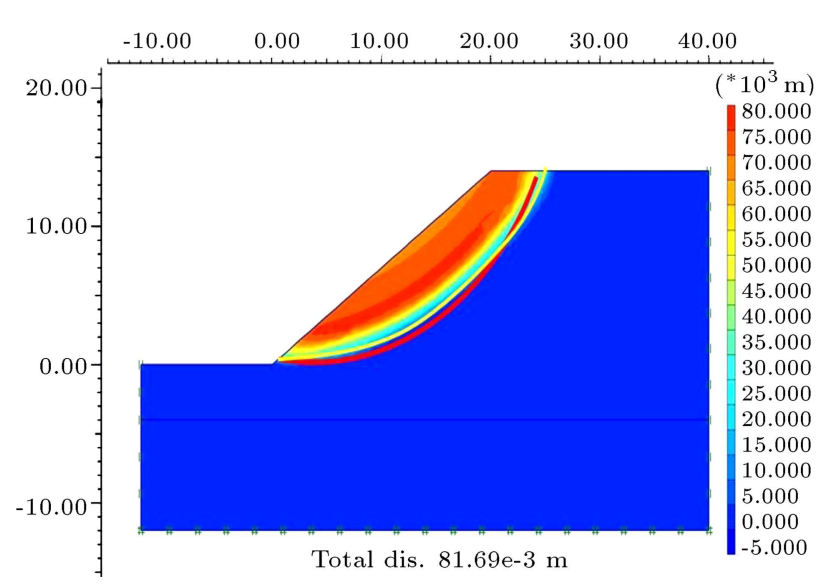

Figure 10. Critical slip surface in LE method (yellow line) and SSR method (red line).

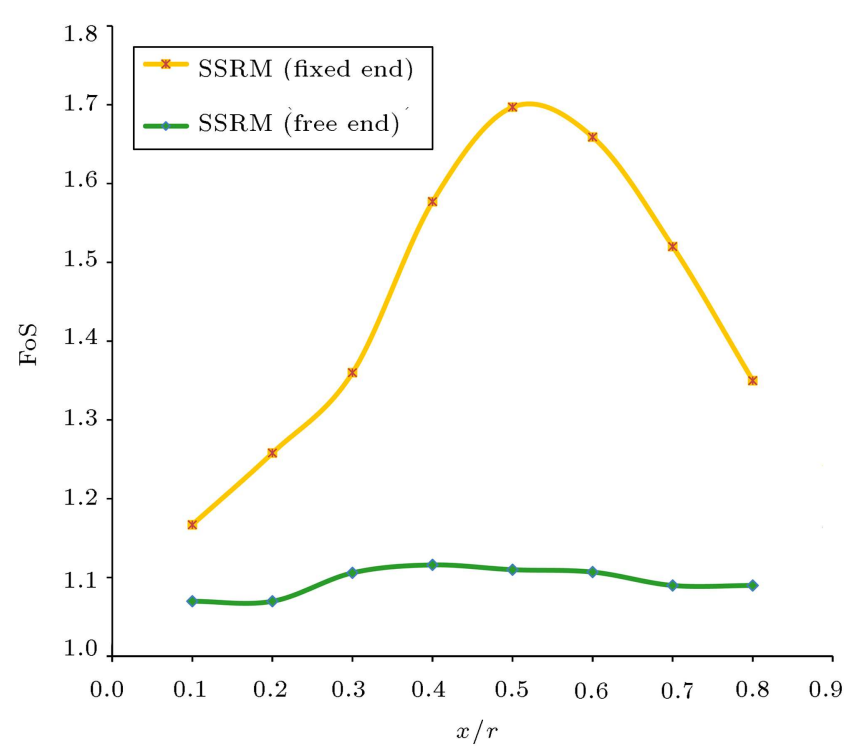

Figure 11. Comparison of the results of the SSR method for fixed-end and free-end for $L=1.5 \mathrm{H}$.

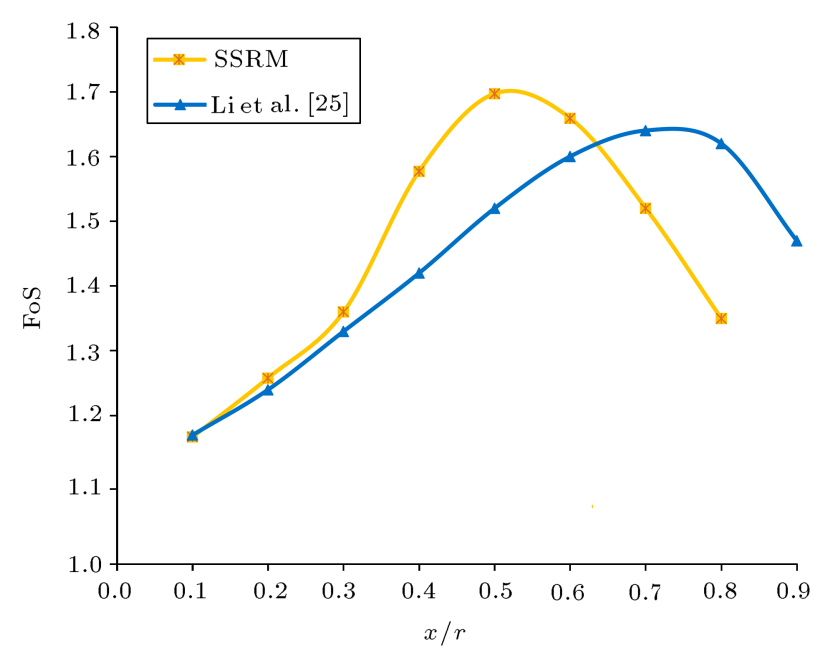

Figure 12. Comparison of SSR method for fixed-end pile condition with a length of $1.5 \mathrm{H}$ and reference [25] with a length of $2 H$. 
Table 1. Variations of pile reliability length and factor of safety for free-tip and fixed-tip.

\begin{tabular}{cccc}
\hline $\begin{array}{c}\text { Length of } \\
\text { pile }(\boldsymbol{L})\end{array}$ & $\begin{array}{c}\text { FoS for } \\
\text { free-tip }\end{array}$ & $\begin{array}{c}\text { FoS for } \\
\text { fixed-tip }\end{array}$ & $\begin{array}{c}\text { Percentage } \\
\text { of change }\end{array}$ \\
\hline$H+1 D$ & 1.07 & 1.69 & $58 \%$ \\
$H+2 D$ & 1.08 & 1.68 & $55 \%$ \\
$H+3 D$ & 1.09 & 1.69 & $55 \%$ \\
$H+4 D$ & 1.1 & 1.7 & $54 \%$ \\
$H+5 D$ & 1.11 & 1.7 & $54 \%$ \\
\hline
\end{tabular}

of safety, one of the main objectives of stabilization, i.e., cost reduction, is achieved. As seen in Figure 12, the maximum factor of safety belongs to the piles that are installed in the middle of the slope. In Figure 12, which shows that the highest factor of safety belongs to $\frac{x}{r}=0.5$, variations of the reliability length $\left(L_{e}\right)$ below the critical slip surface are examined in proportion to the factor of safety values. At each phase, the pile reliability length $\left(L_{e}\right)$ is increased by $1 \times D$. Table 1 presents the variations of pile reliability length and factor of safety.

As seen in Table 1, in the case of a fixed-end pile, increase in $L_{e}$ does not significantly contribute to the increase in the factor of safety value. Due to implementation reasons, it is necessary to have a pile reliability length that makes it possible to embed the pile in a depth two times the pile diameter in the layer below the critical slip surface to ensure that the slip band will be above reliability length of the end of pile.

\subsubsection{Determining the most effective location for pile installation}

The most effective location for pile installation is the place that not only gives the required factor of safety, but also uses the minimum pile length. As it was described, the factor of safety in a homogenous soil can be significantly increased by fixing the pile end and reducing its length. Although the process of fixing pile end is time-consuming and requires precision, the resulting significant increase in factor of safety and reduction in stabilization costs are the reasons that justify it. As seen in Figures 13 and 14, a horizontal plane can give the required factor of safety. The point that the plane collides with the curve gives the coordinates of different pile lengths and locations. The place with the shortest pile length is the most effective for pile installation.

\subsection{Example 2}

The three-layer earth slope studied in this example is depicted in Figure 15. The strength parameters of the third layer are larger than those of the other two layers. The slope height is $10 \mathrm{~m}$ and its angle is 34 degrees. The physical characteristics of the layers are presented in Table 2. The figures of numerical analyses using SLOPW and FDM programs are shown

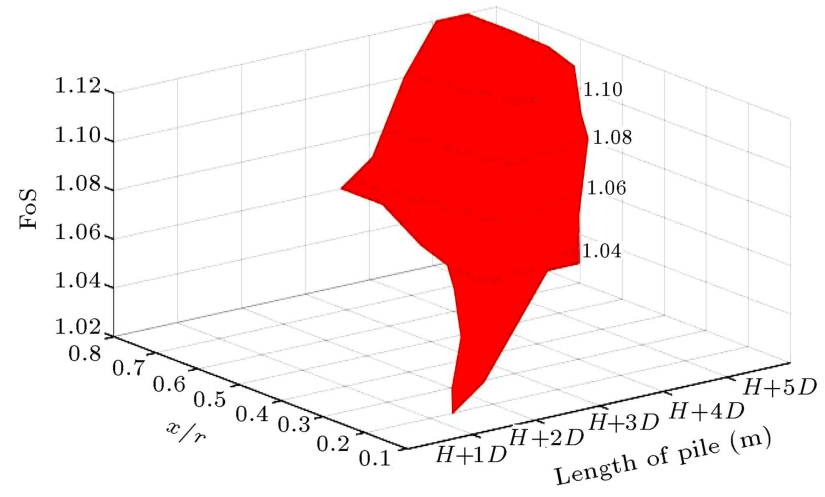

Figure 13. Three-dimensional diagram of free-end pile length $(L)$, pile location $(x / r)$, and Factor of Safety (FoS) in Example 1.

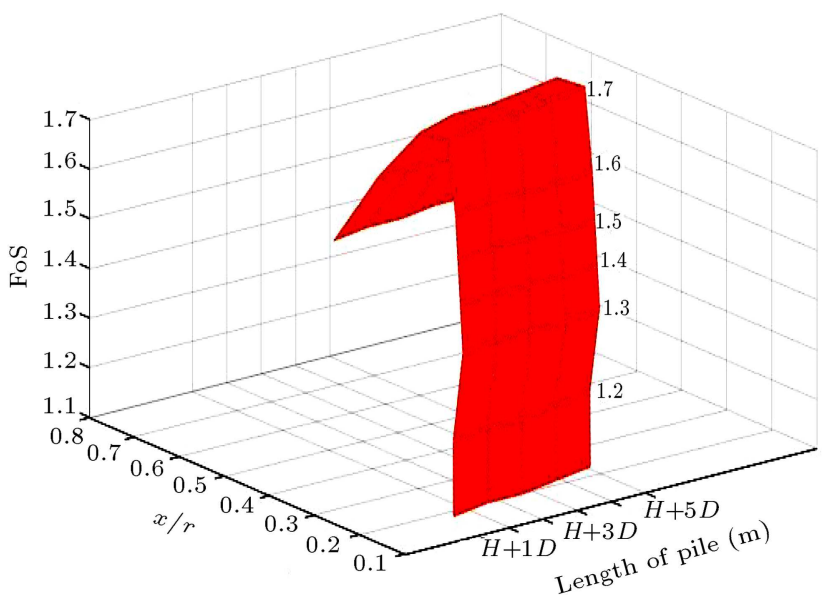

Figure 14. Three-dimensional diagram of fixed-end pile length $(L)$, pile location $(x / r)$, and Factor of Safety (FoS) in Example 1.

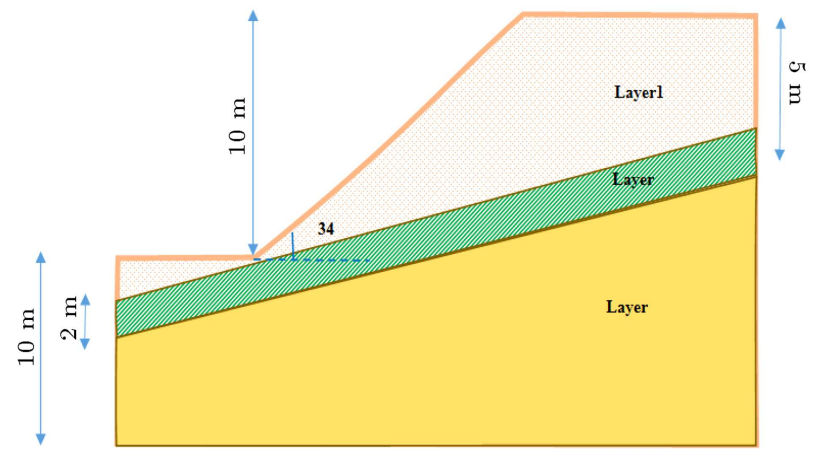

Figure 15. Three-layer earth slope geometry in Example 2.

in Figure 16. The minimum factors of safety for LE and SSR methods are calculated at 0.88 and 0.75 , respectively.

\subsubsection{Analysis of the effect of fixed pile tip}

In this example, the third layer, which lies at the bottom of the pile, has the largest strength parameters. Figure 17 shows the results of modeling a pile for 
Table 2. Shear strength parameters of earth slope in Example 2.

\begin{tabular}{cccccc}
\hline $\begin{array}{c}\text { Layer } \\
\text { no. }\end{array}$ & $\begin{array}{c}\text { Cohesion } \\
(\mathbf{k P a})\end{array}$ & $\begin{array}{c}\text { Friction angle } \\
(\mathbf{d e g r e e})\end{array}$ & $\begin{array}{c}\text { Unit weight } \\
\left(\mathbf{k N} / \mathbf{m}^{\mathbf{3}}\right)\end{array}$ & $\begin{array}{c}\text { Poisson's } \\
\text { ratio }\end{array}$ & $\begin{array}{c}\text { Elasticity modulus } \\
\left(\mathbf{k N} / \mathbf{m}^{\mathbf{2}}\right)\end{array}$ \\
\hline Layer 1 & 29.4 & 12 & 18.8 & 0.3 & 12000 \\
Layer 2 & 9.8 & 5 & 18.8 & 0.3 & 12000 \\
Layer 3 & 29.4 & 40 & 18.8 & 0.3 & 12000 \\
\hline
\end{tabular}

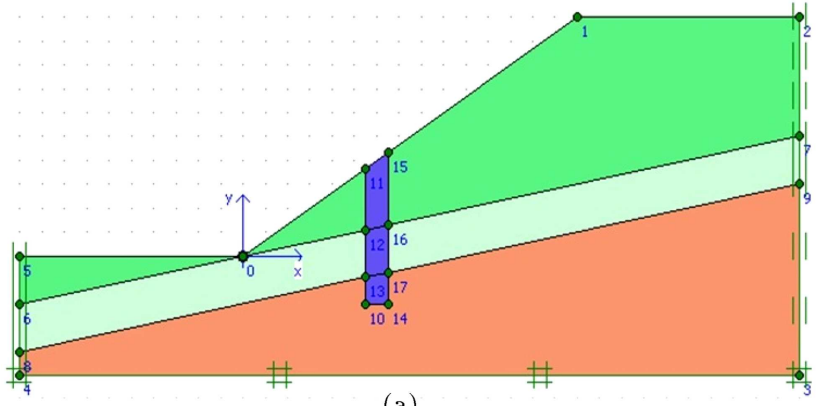

(a)

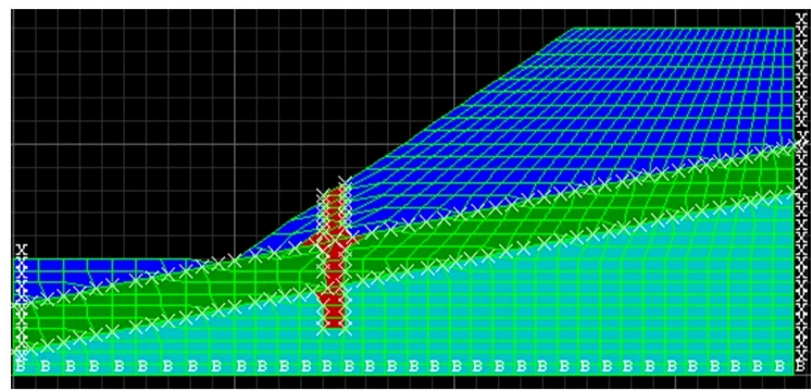

(b)

Figure 16. Numerical analysis for Example 2: (a) SLOPEW, and (b) FDM softwares.

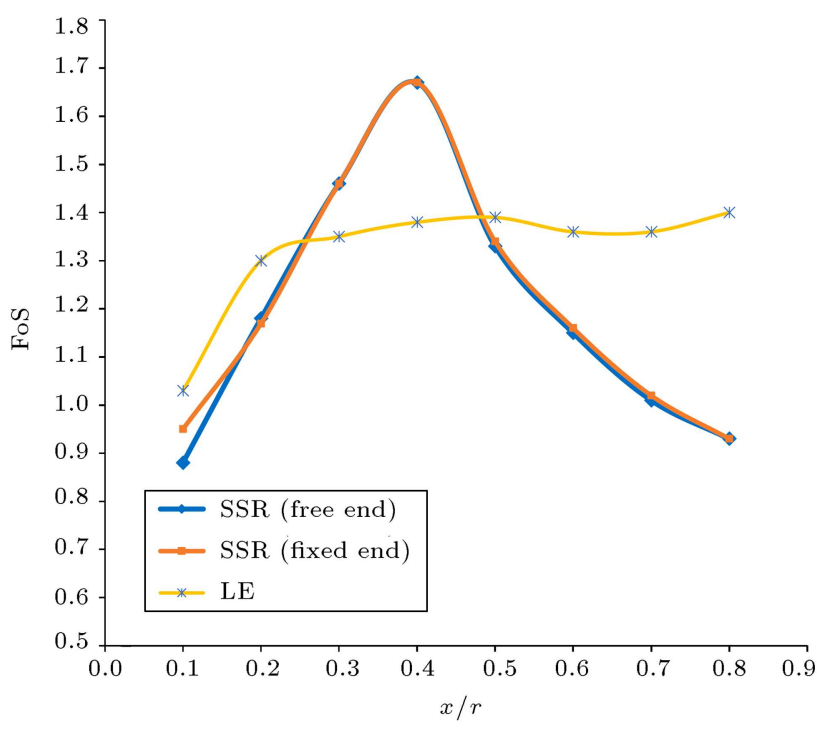

Figure 17. Comparison of LE and SSR methods for different locations and $L=1.5 \mathrm{H}$ in free-end and fixed-end conditions.

different locations $(0.1 \leq x / r \leq 0.8)$ and $L=1.5 H$ in free-end and fixed-end conditions.

As seen in Figure 17, fixing the pile end does not

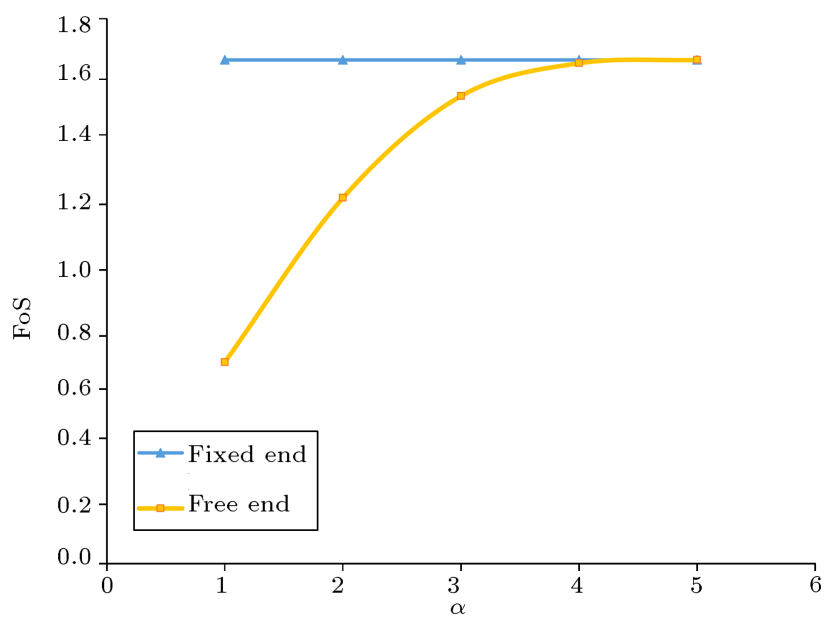

Figure 18. Variations of pile reliability length $\left(L_{e}=\alpha D\right)$ and FoS for the fixed-end and free-end piles.

leave a significant effect on the value of factor of safety. The reason is that emplacing the pile end into a layer with large strength parameters is the same as fixing the pile end. As seen in Figure 17, at $\frac{x}{r}=0.1$, the results obtained for fixed-end pile do not very well comply with the results of the free-end pile. The reason is that the length required for emplacing the pile end into the third layer is not achieved.

Figure 17 indicates that the largest factor of safety belongs to $\frac{x}{r}=0.4$. Hence, the variations of reliability length $\left(L_{e}\right)$ are studied based on the factor of safety of $\frac{x}{r}=0.4$. Results of the variations of reliability length $\left(L_{e}\right)$ are depicted in Figure 18. As seen in this figure, in the case of the fixed-end pile, increase in the reliability length does not have a significant effect on the increase in the factor of safety. However, in the case of the free-end pile, increase in the pile length leads to the growth of safety factor. The maximum factor of safety is also achieved with $L=H+4 D$ and with length values higher than $H+4 D$, the factor of safety remains unchanged. The increase in the factor of safety is a result of the collision between pile end and the dense layer. A comparison between Figures 15 and 16 indicates that to achieve a safety factor of 1.2 for a free pile tip, it is necessary to choose a pile with a length $5 D$ longer than the fixed pile tip. If the pile diameter is considered 1 meter, the volume of reinforced concrete will be increased by about 4 cubic meters. Given that implementation of concrete per cubic meter costs 20 dollars, 80 extra dollars will be needed for each pile. 
Thus, 10 piles in a row will cause 800 dollars extra costs.

\subsubsection{Determining the most effective and economical location for pile installation}

As it was explained earlier, if the pile end is embedded in a strong layer, fixing the pile end will not significantly increase the factor of safety (except for the pile end that is fixed in the vicinity of slope toe). According to Figure 17, the safety factor for $\frac{x}{r}=0.4$ is equal to 1.67 . Figures 19 and 20 show the three-dimensional diagram of pile length $(L)$, pile location $(x / r)$, and factor of safety for free-end and fixed-end piles, respectively. In order to find the most effective location for pile installation, the horizontal plane for the factor of safety of interest should be mapped. The most effective location is the one that requires the shortest pile length. In fact, the most effective location not only yields the required factor

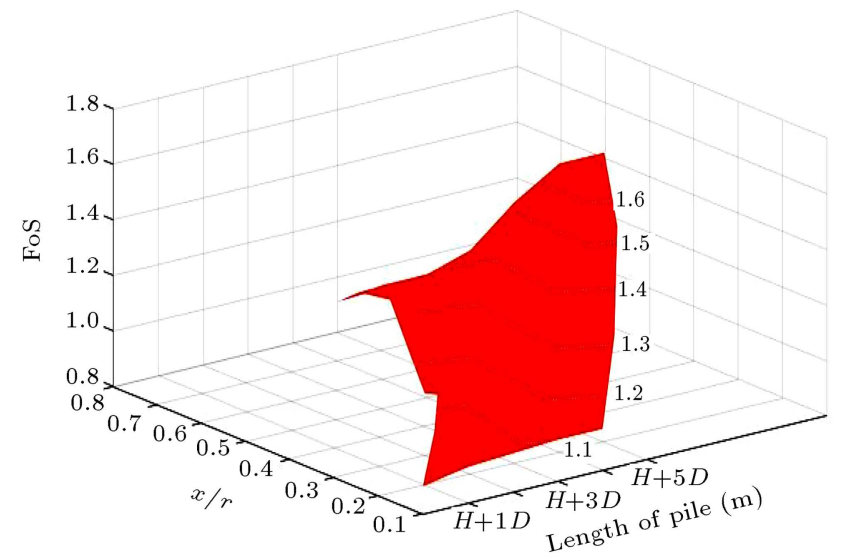

Figure 19. Three-dimensional diagram of pile length $(L)$, pile location $(x / r)$, and Factor of Safety (FoS) for free-end pile.

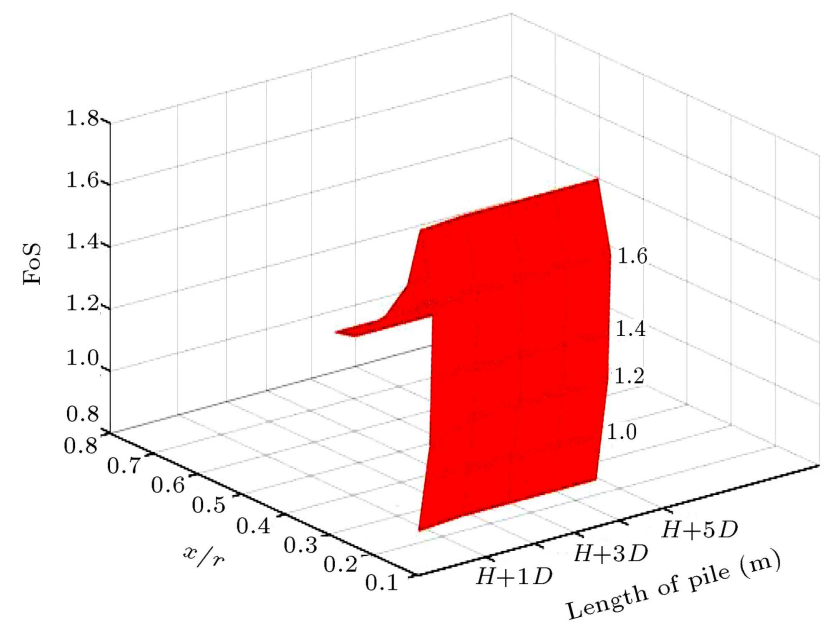

Figure 20. Three-dimensional diagram of pile length $(L)$, pile location $(x / r)$, and Factor of Safety (FoS) for fixed-end pile. of safety, but also provides for the determination of the shortest pile length and reduction in stabilization costs.

\section{Conclusion}

In this paper, the minimum stabilization pile length was achieved by a new proper method. Fixing pile tip was a method that helped to reduce stabilization costs. Then, the most effective location that required the shortest length was found by mapping the threedimensional diagram of pile length, pile location, and factor of safety. In order to obtain the maximum factor of safety for a row of free-end piles in homogenous slopes, the piles should be placed near slope crown or in the middle of the slope. If the piles are installed in inappropriate location with inadequate length, the factor of safety decreases, instead of increasing.

Fixing pile tips in homogenous slopes could increase factor of safety by up to $55 \%$. As a result, pile length and stabilization costs would be reduced. It should be mentioned that fixing pile tips should be done with adequate care. If the end of a pile in a nonhomogeneous slope is emplaced into a dense layer, the required reliability length will be achieved. In such cases, fixing pile tip will not significantly increase the factor of safety. However, if the pile tip is embedded into soft layer, fixing pile tips can increase the safety factor by up to $55 \%$.

\section{References}

1. Hajiazizi, M., Kilanehei, P., and Kilanehei, F. "A new method for three dimensional stability analysis of earth slopes", Scientia Iranica, 25(1), pp. 129-139 (2018).

2. Ghanbari, E. and Hamidi, A. "Stability analysis of dry sandy slopes adjacent to dynamic compaction process", Scientia Iranica, 24(1), pp. 82-95 (2017).

3. Zhang, G. and Wang, L. "Integrated analysis of a coupled mechanism for the failure processes of pilereinforced slopes", Acta Geotechnica, 11(4), pp. 941952 (2016).

4. Wang, L. and Zhang, G. "Progressive failure behavior of pile-reinforced clay slopes under surface load conditions", Environmental Earth Sciences, 71(12), pp. 5007-5016 (2014).

5. Xu, J. and Niu, F. "Safety factor calculation of soil slope reinforced with piles based on Hill's model theory", Environmental Earth Sciences, 71(8), pp. 3423-3428 (2014).

6. Xiao, S. "A simplified approach for stability analysis of slopes reinforced with one row of embedded stabilizing piles", Bulletin of Engineering Geology and the Environment, pp. 1-12 (2016).

7. Chen, C., Xia, Y., B, V.M. "Slope stability analysis by polar slice method in rotational failure mechanism", Computers and Geotechnics, 81, pp. 188-194 (2017). 
8. Chen, L.T., Poulos, H.G., and Hull, T.S. "Model tests on pile groups subjected to lateral soil movement", Soils and Foundation, 37(1), pp. 1-12 (1997).

9. Chen, C.Y. and Martin, G.R. "Soil-structure interaction for landslide stabilizing piles", Computers and Geotechnics, 29(5), pp. 363-386 (2002).

10. Liang, R. and Zeng, S. "Numerical study of soil arching mechanism in drilled shafts for slope stabilization", Soils and Foundations, 42(2), pp. 83-92 (2002).

11. Verveckaite, N., Amsiejus, J., and Stragys, V. "Stressstrain analysis in the soil sample during laboratory testing", J. of Civil Engineering and Management, 13(1), pp. 63-70 (2007).

12. Kahyaoglu, M.R., Imancli, G., Ozturk, A.U., and Kayalar, A.S. "Computational 3D finite element analyses of model passive piles", Computational Materials Science, 46(1), pp. 193-202 (2009).

13. Kahyaoglu, M.R., Onal, O., Imançlı, G., Ozden, G., and Kayalar, A.S. "Soil arching and load transfer mechanism for slope stabilized with piles", J. of Civil Engineering and Management, 18(5), pp. 701-708 (2012).

14. Kourkoulis, R., Gelagoti F., Anastasopoulos I., and Gazetas, G. "Hybrid method for analysis and design of slope stabilizing piles", J. of Geotechnical and Geoenvironmental Engineering, 138(1), pp. 1-14 (2012).

15. De Beer, E.E. and Wallays, M. "Forces induced in piles by unsymmetrical surcharges on the soil round the piles", Conf. on Soil Mechanics and Foundation Engineering, 1, Spanish Society for Soil Mechanics and Foundations, Madrid, Spain, pp. 325-332 (1972).

16. Ito, T. and Matsui, T. "Methods to estimate lateral force acting on stabilizing piles", Soils and Foundations, 15(4), pp. 43-60 (1975).

17. Hassiotis, S., Chameau, J.L., and Gunaratne, M. "Design method for stabilization of slopes with piles", Geotech. Geoenviron. Eng., 123(4), pp. 314-323 (1997).

18. Chen, L.T., Poulos, H.G., and Hull, T.S. "Model tests on pile groups subjected to lateral soil movement", Soils and Foundation, 37(1), pp. 1-12 (1997).

19. Poulos, H.G. "Design of reinforcing piles to increase slope stability", Can Geotech J., 32(5) pp. 808-818 (1995).

20. Tschebotarioff, G.P., Foundations, Retaining and Earth Structures, McGraw Hill, New York (1973).

21. Fakhimi, A., Continuum Analysis 2-DimensionalTheory and User's Manual, BHRC Publication, Iran (2001).

22. Poulos, H.G. and Chen, L.T. "Pile response due to excavation induced lateral soil movement", Geotech. Geoenviron. Eng., 123(2), pp. 94-99 (1997).

23. Goh, A.T.C., The, C.I., and Wong, K.S. "Analysis of piles subjected to embankment induced lateral soil movements", Geotech. Geoenviron. Eng., 123(4), pp. 312-323 (1997).
24. Hajiazizi, M. and Mazaheri, A.R. "Use of line segments slip surface for optimized design of piles in stabilization of earth slopes", International Journal of Civil Engineering, Geotechnical Engineering, 13(1), pp. 1427 (2015).

25. Li, X., Pei, X., Gutierrez, M., and He, S. "Optimal location of piles in slope stabilization by limit analysis", Acta Geotechnica, 7(3), pp. 253-259 (2012).

26. Hassiotis, S., Chameau, J.L. and Gunaratne, M. "Design method for stabilization of slopes with piles", Geotech. Geoenviron. Eng. ASCE, 123(4), pp. 314-323 (1997).

27. Poulos, H.G. "Design of slope stabilizing piles", Slope Stability Engineering, N. Yagi, T. Yamagami, and J.C. Jiang, Eds., A. A. Balkema, Rotterdam, Netherlands (1999).

28. Reese, L.C., Wang, S.T., and Fouse, J.L. "Use of drilled shafts in stabilizing a slope", Proc., Specialty Conf. on Stability and Performance of Slopes and Embankments II (GSP 31), 2, ASCE, New York, pp. 1318-1332 (1992).

29. Johari, A., Mousavi, S., and Hooshmand Nejad, A. "A seismic slope stability probabilistic model on Bishop's method using analytical approach", Scientia Iranica, 22(3), pp. 728-741 (2015).

30. Reese, L.C. and Van Impe, W.F. "Single piles and pile groups under lateral loading", A. Balkema, Rotterdam, Netherlands (2001).

31. Poulos, H.G. "Analysis of piles in soil undergoing lateral movement", Soil Mech. Found. Div ASCE, 99(5), pp. 391-406 (1973).

32. Ashour, M. and Ardalan, H. "Analysis of pile stabilized slopes based on soil-pile interaction", Computers and Geotechnics, 39, pp. 85-97 (2012).

33. Won, J., You, K., Jeong, S., and Kim, S. "Coupled effects in stability analysis of pile-slope systems", Computers and Geotechnics, 32, pp. 304-315 (2005).

34. Ausilio, E., Conte, E., and Dente, G. "Stability analysis of slopes reinforced with piles", Computers and Geotechnics, 28, pp. 591-611 (2001).

35. Ebadi, M., Habibagahi, G., and Hataf, N. "Effect of cement treatment on soil non-woven geotextile interface", Scientia Iranica A, 22(1), pp. 69-80 (2015).

36. Yildiz, M. and Soganci, A.S. "Improvement of the strength of soils which comprises granular pumice by injection of cement under low pressure", J. Scientia Iranica A, 22(1), pp. 81-91 (2015).

37. Wei, W.B. "Three dimensional slope stability analysis and failure mechanism", Ph.D. Thesis, Hong Kong Polytechnic University, Hong Kong (2008).

38. Wang, M.C., Wu, A.H., and Scheessele, D.J. "Stress and deformation in single piles due to lateral movement of surrounding soils", Behavior of Deep Foundations: ASTM Special Technical Publication, 670, Raymond Lunggren, Ed., ASTM, West Conshohocken, PA, pp. 578-591 (1979). 
39. Popescu, M.E. "Landslide control by means of a row of piles", Slope Stability Engineering: Proc., Int. Conf. on Slope Stability, Thomas Telford, London, pp. 389394 (1991).

40. Li, X., Pei, X., Gutierrez, M., and He, S. "Optimal location of piles in slope stabilization by limit analysis", Acta Geotechnica, 7, pp. 253-259 (2012).

41. Papadopolou, M.C. and Comodromos, E.M. "On the response prediction of horizontally loaded fixed-head pile groups in sands", Computers and Geotechnics, 37, pp. 930-941 (2010).

42. Lee, C.Y., Hull, T.S., and Poulos, H.G. "Simplified pile-slope stability analysis", Computers and Geotechnics, 17, pp. 1-16 (1995).

\section{Biographies}

Mohammad Hajiazizi is Associate Professor of Geotechnical Engineering at Razi University, Kermanshah, Iran. He received his PhD degree in Geotechnical Engineering from Shiraz University under the Supervi- sion of Professors A. Ghahramani and Hataf and his MSc degree in Geotechnical Engineering from Tarbiat Modarres University under the supervision of Professor A. Fakhimi. His current and main research interests are soil improvement, slope stability, tunneling, and meshless methods.

Mosoud Nasiri is $\mathrm{PhD}$ candidate in Geotechnical Engineering at Razi University, Kermanshah, Iran. He received his MSc degree in Geotechnical Engineering from Razi University under the supervision of Dr. M. Hajiazizi.

Ahmad Reza Mazaheri is Assistant Professor of Geotechnical Engineering at Ayatollah Borujerdi University. He received his $\mathrm{PhD}$ degree in Geotechnical Engineering from Razi University under the supervision of Dr. M. Hajiazizi and his MSc degree in Geotechnical Engineering from Amirkabir University of Technology. His current and main research interests are slope stability and soil improvement. 